\title{
ECONOMIA POLITICA
}

\section{CRISES ECONOMICAS}

\author{
No subject of economic discussion has \\ provoked a greater variety of conflicting opi- \\ nions than that of financial crises and periods \\ of depression. \\ Numerous explanations of their causes \\ have been advanced. (Burton. Crises and \\ Depressions) .
}

1) E' sabido que as crises se manifestam com mais força nas sociedades grandemente desenvolvidas do que nas primitivas. Nos tempos primitivos seu equivalente, si nos é permittida a expressão, é a fome. Os 7 annos de risco de fome no Egypto, evitada por José, nada mais são do que a crise do tempo em que era o organismo social summamente simples. Hoje, com a facilidade de transportes, com o desenvolvimento do crédito, considera-se a fome, em tempo de paz, quasi impossivel. Só em caso de sitio, em tempo de guerra, cessadas todas as relações que a civilisação creou entre os povos cultos, é que póde apparecer o phantasma da fome. Neste rapido estudo, mostraremos que as crises são uma necessidade da organização actual apparecendo com um rhythmo regular, embora não tão preciso quanto pensa o vulgo, e tendo o mesmo cunho fatal e dramatico que o crime e outros muitos phenomenos sociaes. Justamente a complexidade crescente da organização economica é que mais difficil torna qualquer remedio para este mal. 
Pôr termo ás crises, do mesmo modo que tornar o crime impossivel, é utopia, com que se embala o espirito dos philantropos do mesmo modo porque, durante seculos, buscou a humanidade a pedra philosophal e o elixir da longa vida.

O que se póde é investigar quaes os meios de obter a diminuição dos crimes e de fazer face aos estragos que a crise traz no organismo social.

2) No correr do seculo XIX, e na aurora deste, á literatura economica enriqueceu-se com avultados estudos sobre o assumpto. No Brasil, tornou-se conhecidissimo o que ensina Gilbart, por ter sido traduzida sua obra sobre bancos para nossa lingua. Gilbart occupou-se do historico das crises, e a explicação da origem dessas calamidades, dada por elle é mais philosophica do que economica. Nascem, entende elle, da cobiça (lust of gold) ou melhor da sacra auri fames. Praticamos loucuras fascinados pelo desejo de riqueza, e cahimos, quando não temos competencia para as arrojadas empresas em que nos envolvemos. São algum tanto pinturescas suas palavras, e por isto mesmo dignas de serem reproduzidas, para prova de sua originalidade. Eil-as: "Covetousness, a maddening desire to bound at once, say from competence to riches, hurries the flies into the meshes cunningly woven for them, and the weak become the victims". Note-se que Gilbart não é, como parece por esta citação, homem que deixe de ter presentes as regras de moral, ao estudar os assumptos economicos. Attendendo, porém, a outros economistas, diremos que se tornou classica a obra de Clemente Juglar, premiada em razão de seu alto valor.

Ultimamente surgiu a de Lescure, volumosissima, e que tem a vantagem sobre a de Juglar, de trazer estudos novos, pelas observações de factos mais recentes, particularmente por ter o autor estudado directamente na 
Allemanha para onde se transportou, a crise de 1910. Além da observação directa, teve o autor a vantagem dos minuciosos estudos feitos naquelle paiz, das observações rigorosas, das estatisticas, das monographias, da systematização, quiçá excessiva por vezes.

Não nos illudamos, julgando que, sobre o assumpto, ha meia duzia de obras. Lescure cita uma bibliotheca, ao apresentar a lista das obras sobre a materia. Burton dá cerca de 40 autores que se dedicaram á investigação das causas deste terrivel phenomeno tão temido hoje quanto noutros tempos o eram a peste, a fome e a guerra, e contra o qual se tem indicado perigosos remedios, como são os cartells e os trusts, assim como contra a lepra se receitou picada de cascavel!... Não é, nem póde ser nossa intenção, escrevendo um pequeno artigo, sinão dar uma rapida idéa do que seja uma crise, e do modo por que actua sobre o organismo social, particularmente sobre a vida economica.

3) Todos sabemos vagamente o que é uma crise, mas não temos do phenomeno uma clara ou precisa idéa. E' mesmo interessante observar que, quando se dão essas convulsões economicas, as pessôas que se aproveitam dellas negam, em bôa fé, que haja crise. São os prejudicados pela perturbação que affirmam sua existencia.

Antes de tudo, cumpre firmar que, em geral, só se considera crise uma perturbação transitoria, cuja duração, exacta não podemos fixar, mas que, desde que se prolongue, é denominada depressão. 0 estado de pobresa de um paiz, de nenhum modo póde ser confundido com uma crise. E' vulgar falar-se indifferentemente em crise e panico. Isto, porém, é uma confusão de idéas inteiramente diversas.

O panico é o temor subito, que, as mais das vezes, não tem causa real, ou que é inteiramente infundado, e cuja consequencia é accentuar-se a perturbação econo- 
mica, ou mesmo produzir-se tal perturbação quando não existe, quando não é determinada por motivos reaes.

$\mathrm{O}$ vocabulo panico substitue com frequencia a expressão crise por um euphemismo: quer-se dest'arte significar que não ha verdadeira crise, mas temor vão, temor que leva a crer na existencia della. $O$ que é fóra de duvida, digamos de passagem, é que o panico sempre se mostra em qualquer modificação importante das condições economicas, e é factor constante na evolução da crise.

Em tal caso, dá-se exactamente o que occorre com as demais calamidades, e exemplos frisantes temos nas epidemias, em que, a par das victimas da molestia, ha as do panico. A modificação da porcentagem dos crimes, dos suicidios, dos casamentos, que se nota nas crises é em grande parte devida ao panico. O panico é uma emoção, um estado de espirito, um phenomeno psychologico, quer tenha fundamento, quer não passe de méra allucinação. A crise é uma realidade, pertẹncente ao mundo objectivo, dá-se fóra de nós. Celebre se tornou a definição de crise dada por Stuart Mill, a qual é entretanto só referente ás commerciaes, e ainda que não houvesse sido composta com a preoccupação de fazimento de uma definição com os requisitos classicos exigidos pela Logica, dá clara idéa do phenomeno. "There is said to be a commercial crises when a great number of merchants and traders at once either have, or apprehend that they shall have, a difficulty in meeting their engagements". Para o grande mestre pois já ha crise, desde que se produz o panico, ou apprehensão de não poder fazer face aos compromissos. Stuart Mill toma, pois, a causa pelo effeito. Refere-se exclusivamente ás crises commerciaes, donde concluir que a explicação por elle apresentada para determinar o que seja uma crise é, a certa luz, ampla de mais, e, a outra, restricta em excesso. O que é certo é que, no meio das duvidas, do vago, do indeterminado do que seja uma crise, todos estão de accôrdo em que ella se dá 
quando ha uma subita modificação das condições economicas de um paiz, referindo-se o vocabulo particularmente, "to times of difficulty, insecurity, and suspense in politics or commerce", como diz Murray. A isto cumpre accrescentar que nem sempre o vocabulo no uso vulgar para assumptos não economicos, é empregado no sentido pejorativo, mas que, em materia economica, elle envolve sempre a idéa de calamidade pública. Abaixo veremos que a crise é um mal, contestando a opinião contrária, que aliás tem seus partidarios. A idéa de crise é summamente complexa, porque suppõe eonhecimento dos principios que regem o valor, a producção, o consumo, a repartição, a circulação, sobretudo o meio circulante.

Sabemos todos que, em geral, pensa o povo que a crise é devida unioamente a guardarem os particulares o dinheiro no pé de meia; e os bancos, em șeus cofres. Os mais rusticos pensam mesmo que ha falta de dinheiro, e não vão até chegar, por esforço de imaginação, aos penetraes onde deve estar o numerario: sumiu-se todo o dinheiro, dizem, com aquella singeleza das almas candidas, que não fazem investigações.

4) Para methodo neste trabalho, convém especificar as varias fórmas das crises. Podemos apresentar como sendo classes differentes a agricola, resultante do augmento ou diminuição na producção ou no consumo dos productos agricolas; a commercial ou mercantil, relativa ao commercio que não o bancario; a financeira que geralmente é chamada bancaria, pois é aos bancos que, em regra, toca o commercio de dinheiro, e é relativo ao meio circulante este genero de crises; a industrial, resultante de alterações subitas nas condições das industrias, ou de um ramo de industrias. Não nos esqueçamos, porém, e é tal circumstancia de grande valor, que uma especie de crise póde gerar outra. Uma superproducção agricola póde determinar uma perturbação profunda no com- 
mercio. Figuremos, em nosso Estado, um colossal augmento da producção do café. As consequencias possiveis seriam perturbação dos preços com tendencia para a baixa, abalo das casas commerciaes que negociam em tal mercadoria, prejuizos para os bancos que fornecem dinheirc para essas casas, perturbação profunda nos demais negocios commerciaes, pois todos têm relações, mais ou menos estreitas, com a sorte de nosso principal producto, perturbação das industrias, particularmente das que mais directamente têm relações com a lavoura cafeeira, como é a das machinas agricolas, etc. Outro exemplo é o da crise monetaria determinando superproducção, e esta alterando profundamente a vida economica.

Costumam os europeos dar como exemplo da influencia de crise determinada pelo subito augmento do meio circulante, a de 1825, occasionada pela descoberta de minas de prata no Mexico, e consequentemente pela possibilidade do desenvolvimento ou applicação das descobertas feitas no principio do seculo XIX, vapor, estradas de ferro, machinas, etc. Nós poderemos dar um exemplo mais modesto: é o da bolsa ou do ensilhamento. O excesso de papel moeda determinou o apparecimento das loucas empresas, a creação de fabricas sem elementos de vida, a cultura em escala elevadissima de terras que não poderiam dar remuneração, e emfim a applicação nas indusurias de pessôas incompetentes. Casos houve em que o producto não valia a materia prima nelle „empregada. A crise, pois, póde ser geral, e melhor será dizer, tendo-se em consideração a estreita dependencia em "que se acham varios phenomenos economicos, que é ella, com frequencia, geral, pela intima relação que ha entre as varias industrias.

5) Uma das questões que têm apaixonado o público é saber si a crise é um mal ou um bem. Dois argumentos ouvimos quasi sempre para a demonstração de que crise 
é um bem, e acham-se elles mesmo mencionados por economistas, comquanto sejam offerecidos por bons sómente pelas pessôas de poucos conhecimentos economicos. O primeiro é que a crise estimula a actividade. Ora isto equivale a dizer que é bom que os vehiculos pisem os transeuntes, porque a morte de alguns faz que os outros estuguem o passo, fiquem mais activos e cautelosos. O segundo argumento é tirado da circumstancia de ganharem uns individuos accidentalmente nesses periodos angustiosos: assim o retalhista ganha, em caso de alta dos preços, vendendo com enorme lucro a mercadoria que tinha em deposito. Esta pequena vantagem de um numero limitadissimo de pessôas não póde significar proveito geral.

Este mesmo retalhista vae depois soffrer com as consequencias da crise, pois verá, mais tarde, diminuido seu lucro pela reducção das vendas, consequencia da alta dos preços. A communhão social soffre, e não devemos nos esquecer desta verdade formulada por Burton, ao estudar a questão que nos occupa: "The prosperity of the whole community is the prosperity of every part". Ora o que observamos, quando se manifesta uma crise, é, ao lado do retalhista que tem um pequeno lucro, vendendo mais caro, ao lado do usurario que consegue emprestar a algum infeliz por uma taxa mais elevada, o industrial com suas machinas paradas, a venda de productos agricolas e de todos os generos diminuida, o operario sem trabalho, tudo emfim, paralysado, e o panico pintado em todos os rostos. Tão horrivel estado de coisas não póde ser desejado. A crise é pois um mal. Ao contrario, o que devemos buscar é que não se dêem esses desequilibrios entre a producção e o consumo, mantendo-se quanto possivel, justa proporção entre ambos, de modo a não haver na sociedade convulsões economicas, sinão muito menos accentuadamente do que até agora. Nosso fim, ao lançarmos este artigo, é provar que não ha um remedio para as crises, mas que é perfeitamente possivel diminuir-lhes a intensi- 
dade, melhorando as condições economicas. Quem, ha 200 annos, dissesse que um tempo viria em que a fome difficilmente se apresentaria apavorando a um paiz, passaria por um sonhador. Pois bem! O telegrapho, a navegação a vapor, a estrada de ferro, e, cooperando com esses inventos, o progresso na organização economica, o desenvolvimento do credito, os institutos de credito, os institutos mercantis internacionaes, o serviço de publicidade, as grandes forças pecuniarias obtidas pelas sociedades anonymas, tiveram como consequencia tornar um fossil a abantesma a que deveu José sua elevação politica no Egypto. Opportuno é o momento do estudo, porque, no correr do seculo XIX, muito se accentuaram as crises, tornando-se até dos mais prementes problemas economicos. Neste sentido, como sendo a crise um effeito do grande desenvolvimento economico d'as nações, é que póde ser recebida a affirmação de Clemente Juglar de que, por mais paradoxal que seja, a riqueza das nações deve ser medida pela violencia de suas crises. $\mathrm{O}$ seculo que findou. e o que começa constituem periodos de desenvolvimento febril. Devemos fazer o equilibrio das varias forças que actuam agora na evolução economica dos povos, adaptar tudo ás nossas necessidades. Ésta perturbação de equilibrio (disturbance of equilibrium) exigindo readaptação ás novas condições (read justment to new conditions), é muito difficil de ser remediada. Emquanto a sociedade progredir, por mais que aperfeiçôe seu mecanismo economico, terá de proceder a essas adaptações por meio de tentativas, mais ou menos felizes, e as menos felizes serão determinadoras de crises.

6) Entremos no ponto fundamental da matéria, onde a difficuldade é extrema e onde disparatam quasi todos os economistas, como, com raro pico, reconhece Burton. Examinemos as causas das crises. Preliminarmente deveremos precatar o leitor contra a opinião vulgar 
sobre o que seja a causa de um phenomeno. Não fôra tão vulgar o erro sobre a noção de causa até o ponto de ser considerada por Bain como constituindo matéria importante a noção prática ou vulgar da casualidade, deixariamos o assumpto para a Logica. Entende-se geralmente ou vulgarmente por causa a circumstancia que parece mais importante, a que é julgada essencial, indispensavel para que houvesse o phenomeno. Si um individuo morre de uma punhalada, diz-se que o golpe foi a causa da morte, e deixam-se na penumbra as outras circumstancias que parecem secundarias: a circulação do sangue, as demais condiçóes do organismo da victima, o bom estado da arma que cortou os vasos, ou abriu caminho a uma infecção. Scientificamente, causas são as varias condições para que se dê o phenomeno, attendendo-se ainda ao que é denominado sua collação ou a fórma por que estão dispostos os factores, as forças, os agentes, no tempo e no logar. Scientificamente, pois, a causa de um phenomeno é o conjuncto de condições para sua producçãö. Vulgarmente é o factor que nos parece mais importante, ficando os outros como sendo condições. Ora, em muitos casos, nenhuma desvantagem ha em denominar causa um dos factores, como exemplo dizendo que o calor é a causa das avalanches, visto como todas as demais circumstancias, ou outros factores, coefficientes do phenomeno, estão bem claros em nosso espirito. Não assim quando dizemos que foi a abundancia de numerario, ou sua falta, que determinou a crise, pois ha então muitas circumstancias que não são rapidamente apprehendidas. $\mathrm{O}$ caso da quitandeira que disse estarem as bananas por preço elevado em consequencia da baixa do cambio, é a prova do perigo do destaque de uma das condições de existencia de um phenomeno para o elevar á categoria de causa, fazendo dos outros condições ou cortezãos desse rei, que é o factor elevado ás honras supremas de causa. 
Qualquer pessôa, mesmo de pequena cultura economica, reconhece que a quitandeira tinha razão quando dizia que o cambio influia no preço das fructas que não eram importadas, mas deixava ella na penumbra esses diversos elementos, que o vulgo considera condições do phenomeno: é o caso da lei de substituição. Ainda ha, neste ponto, outro escolho a evitar. Quando Gilbart foi buscar as causas das crises na tendencia do homem para adquirir riquezas, chegou a tão remoto principio que pouca vantagem poderia, com sua concepção, dar para a solução do problema, pois ninguem vae pensar em estirpar, nem mesmo em attenuar essa inclinação natural do homem. Quando ao contrario, foi dito que as crises são causadas pela perturbação da relação entre a offerta e a procura, nada se adeantou, porque essa perturbação é a propria crise, que deve ser remediada. O que convém, pois, é determinar, fixar, no systéma economico, quaes as condições que, em dadas hypotheses, collocadas no tempo e no logar por certo modo, geram essas convulsões economicas, que denominamos crises, produzindo máo estar para a maioria dos membros da sociedade, interrompendo a producção, levando muitos homens ao desespero e aos actos de loucura. Essa determinação é feita ao intento de modificarmos, nos limites do possivel, as condições economicas de qualquer sociedade, desde que reconheçamos que a podem levar á crise. Vamos ver, no decurso deste estudo, que é este com effeito, o caminho que, embora com certas hesitações e falsas observações, têm seguido os economistas que se occupam com o assumpto.

7) Diz-se que as crises ora são geradas por uma perturbação da relação entre a offerta e a procura, ora por um excesso, ou uma falta de numerario. Póde haver excesso de producção e diminuição excepcional de procura ou de consumo, ou, ao contrario, diminuição da producção e augmento da procura. Ainda póde se dar 
uma diminuição ou augmento geral, ou sómente dar-se a perturbação relativamente a um unico producto. Ora não nos parece que essa classificação de crises seja bôa.

Com effeitó o augmentò do numerario, quer se dê em relação propriamente aos metaes, como succedeu no caso acima mencionado da descoberta das minas de prata no Mexico, ou no caso celebre da Hespanha, quando se viu inundada pelo ouro da America, quer por uma simples emissão de papel moeda, como succedeu no Brasil em 1890, terá como consequencia natural alteração profunda na producção e no consumo. Para o economista o que ha, na vida economica, é a troca, nada mais sendo o dinheiro do que o meio de facilitar a permuta de productos.

8) Classificação analoga á que vem referida no numero antecedente é a das theorias sobre crises. Querem os economistas que haja as escolas organicas e as inorganicas, dizendo estas que a crise é a consequencia da perturbação entre a offerta e a procura, e examinando, como acima fizemos, quaes as modalidades desta perturbação; e attribuindo aquellas as crises a defeitos na organização economica, com vistas parciaes, e preconceitos de socialismo exagerado. Ora não nos parece razoavel ésta distincção. Os filiados ás doutrinas inorganicas, nada mais fazem do que affirmar um facto incontestavel, que é a perturbação entre a offerta e a procura, unica lei do valor. Não negam, é bom ficar isto bem claro, e nunca é de mais accentuar, que o Estado e os homens de sciencia possam cooperar para a modificação, dentro de certos limites, da relação entre a offerta e a procura. Não vemos, pois, como julgar que sustentar que a crise provém de uma ruptura de equilibrio, ou antes seja constituida por essa ruptura, signifique que se entenda dever deixar agir, em toda a sua brutalidade, a lucta pela existencia, a eliminação dos mais fracos. Quando se dá como uma 
das mais importantes causas da crise a tendencia para baixa dos productos pela concurrencia em toda sua violencia, a oppressão do trabalhador no contracto de salario, a producção exagerada pelas machinas e pelo augmento illimitado do capital, diz-se uma verdade. O erro está em sustentar que um só desses factos é o determinador das crises, e vir com o remedio dos cartells ou dos trusts. Em nossa opinião, o que cumpre é estudar o organismo economico, investigar, com agudeza, quaes os factores da perturbação dos preços, e, dentro dos limites em que o individuo póde modificar a acção da evolução da vida social, actuar para combater os coefficientes desses desiquilibrios entre a offerta e a procura. E' isto difficil, muito difficil, mas não significa, que não seja bom o methodo. Porque um operador, um calculista errou em um calculo, em uma conta, não se segue que os processos dados pela Arithmetica e pela Algebra não sejam bons. Em sua Logica sustenta Stuart Mill que, si um ente pudesse conhecer todos os elementos factores dos phenomenos sociaes e sua collocação, poderia, de antemão, prevêr todos os phenomenos, mas, em nota, accrescenta que é preciso eliminar a vontade humana, desde que não se entenda que ella é tambem arrastada pelos moveis que actuam sobre os outros seres, ou desde que se repilla o determinismo. Ora, sendo eu filiado á escola do livre arbitrio, não posso deixar de dar á acção modificadora do homem uma influencia decisiva sobre os destinos sociaes. E' á vontade humana que cabe agir sobre os elementos naturaes, observados estes com o maior escrupulo, e sob as regras que regem a observação, para feliz modificação dos successos sociaes, ao intento de conservação, desenvolvimento dos membros da communhão social. Damos, pois, valor a este factor que os deterministas desprezam: o arbitrio humano. Não nos parece, pois, destituido de importancia o estudo que fez Burton sobre os diversos motivos da perturbação entre a offerta e a procura, com 
aquella lucidez, ou aquelle bom senso com que os americanos encaram esses assumptos. Não esqueçamos de que, si é possivel crise chronica, ou, no caso de serem esses vocabulos incompativeis, crises em periodos frequentissimos, é justamente esse phenomeno natural na America do Norte, onde o rapido progresso, o febril desenvolvimento economico, obrigam os homens a um constante "adjustment to new conditions".

9) Com muita graça, refere Burton que, no relatorio de Carrol D. Wright, no inquerito sobre as causas das crises, apparecem as coisas mais extravagantes.

Entre as muitas destacamos: restricção á liberdade das mulheres, falta de conveniente educação dos meninos, defeitos nas leis sobre a tutela das creanças, concessão de passes gratuitos nas estradas de ferro, alta taxa. dos Telegraphos, uso de fumo!... Deixando essas futilidades, examina Burton as causas substanciaes e as circumstancias aggravantes das crises. Já nos manifestámos sobre este modo de dispôr os factores de um phenomeno, mostrando seus inconvenientes. Não acceitando sua classificação, utilizar-nos-emos comtudo de suas observações. Assim, força é reconhecer que tem inteira razão quando faz sentir que ha parcella de verdade em muitas das doutrinas sobre o motivo capital das crises. Vejamos os que enumera. Cita: falta de confiança, abuso de credito, ou por facilidade de bancos ou por excesso de meio circulante, restabelecimento de condições de preços, mudança nos preços por modificação do valor da moeda, retrahimento do meio circulante, ou volume insufficiente de dinheiro, superproducção ou diminuição excepcional do consumo, tendencias psychologicas ou disposição mental da humanidade... Ora, o grande erro dessas theorias é serem insufficientes para a explicação de todas as crises.

E' innegavel que qualquer desses elementos póde representar papel importante no desenvolvimento de uma. 
crise: será, porém, erradissimo dizer que só elle produziu a calamidade. Neste assumpto, como tambem na geração dos demais phenomenos sociaes, devemos ter presente a collocação dos agentes ou das forças, isto é, conforme ficou acima dito, sua existencia em certas condições de tempo e de logar, e a difficuldade de ligar qualquer factor ou coefficiente á producção de um phenomeno social. Concretizemos nosso pensamento. Quando, no começo da conflagração européa, houve o retrahimento do numenario, não seria isto, por si só, motivo para a terrivel crise que sobreveio. Para ella concorreram outros factores: o medo das consequencias da guerra, vagamente entrevistas a circumstancia de termos compromissos a solver em tempo breve, a provavel diminuição do consumo de nosso principal producto pelo difficil transporte para um dos portos, qual o de Hamburgo, onde entrava cerca de um terço de nossas remessas e outros elementos secundarios. Os factores que representam, em uma crise, papel mais importante, são noutra secundarios, e portanto não concordamos com Burton, de os pôr, de antemão, entre as causas substanciaes ou entre as influencias meramente aggravantes. Continuemos a concretizar nosso pensamento. Quando surge uma crise, ou simples alteração de preços, nem sempre é facil ligar o phenoméno á sua verdadeira causa, dissemos acima, e o exemplificaremos. $\mathrm{O}$ vulgo não comprehende, no estudo dos phenomenos economicos, aquillo que é facilmente apprehendido pelos espiritos cultos, como, por exemplo, por que fórma actua o excesso de numerario para gerar miseria, qual a que se mostrou na Hespanha abarrotada pelo ouro americano. Phenomenos, ha, porém, cuja ligação aos verdadeiros factores é impossivel explicar mesmo aos mais cultos economistas. Assim, e é exemplo tirado de assumpto de actualidade, nem todos estão de accôrdo sobre a explicação do porque das nações prosperarem com as perdas das guerras. Ha bons 70 annos apresentou Stuart Mill o problema na Inglaterra, e tratou 
de lhe dar solução, a qual é conhecida de todos quantos não são inteiramente leigos em Economia Politica. Gide occupou-se da questão agora em França, e della cogita tambem Burton. Cada um dellas procura os anneis ou élos que ligam o factor guerra ao phenomeno prosperidade economica. E' fóra de duvida que temos um factor de miseria na guerra, que é o disperdicio de capitaes. Quaes porém, as forças que actuam em sentido contrario de modo a destruirem a acção da guerra? Comprehende-se facilmente que é um caso de composição de causas, locução adoptada pelos logicos á semelhảnça da consagrada composição de forças. Quaes, porém, esses élos, esses anneis? Produzirá a guerra tendencia á economia, desejo de trabalho no homem, e será este factor da prosperidade? Produzirá ella a necessidade de se privar o homem dos productos annuaes e serão esses que constituem a quasi totalidade da riqueza de uma nação? Será que a despeza da guerra esteja prevista, e consequentemente haja da parte da nação a previdencia de refazer com uma intensificação do trabalho o excesso do consumo? Será que essa volta do regimen do contractus ao do status facilite ao Estado o aproveitamento de forças que estavam perdidas sob um regimen mais liberal? Concorrerão todos esses elementos, interpondo-se como consequencias. da guerra e como factores do melhoramento das ccindições economicas do paiz? Eis graves difficuldades ante as quaes se quebra a atilada intelligencia dos economistas. Insistamos neste ponto, que é de summa importancia.

10) Não é facil determinar qual o ponto de desarranjo de um machinismo de certa complicação, um relogio e mesmo uma machina de coser, ou um apparelho electrico... Muito mais difficil é ao medico precisar o ponto em que o organismo humano está perturbado. Que deveremos dizer de desordens no organismo social? Suas causas escaparão necessariamente aos mais agudos espiritos. Quando uma arteria é inutilizada, o membro que 
ella vivificava não perece: a Providencia armou a natureza de forças, e por isto as arteriolas lateraes, ramificações da perdida, entram em funcção e o membro continúa vivo!... Não menos admiravel é a acção das forças naturaes no organismo social. Quando, como acima ficou dito, houve, o temor de que não tivesse consumo grande parte do nosso café recebido pelo porto de Hamburgo, não se pensou na acção das forças naturaes que fizeram com que o producto se escoasse por outros canaes. Não é a acção de um só homem que dirige, neste caso, o destino de um povo ou da humanidade, mas são as forças reunidas de milhões de pessôas. Outras vezes, um só individuo, um só estadista, ou um só economista póde mover o. mundo dando certa orientação ás forças naturaes. Para terminarmos éstas considerações sobre o modo porque actuam uns agentes sobre a producção de certos phenomenos, lembraremos quanto ha de mysterioso nas combinações chimicas, quando se dá ligação ou composição de varias forças (heteropathia), e insistiremos sobre quão mais delicada é essa composição em se tratando de assumptos sociaes.

11) Luctar contra as crises é, cremos, melhorar as coṇdições economicas do paiz, facilitar o conhecimento, por meio de inqueritos, das vicissitudes da vida social, á qual está ligado seu systema economico. E' o conhecimento das necessidades, das exigencias do consumo o guia seguro para o productor.

E' o conhecimento do desenvolvimento das industrias que esclarece o administrador social no augmento ou na diminuição do meio circulante. A par desse conhecimento, está a necessidade de talento, de certo tino, sem o qual não ha estadistas dignos deste nome. E' ahi justamente que se apresenta a maior difficuldade na direcção de um povo. Exactidão, segurança na observação do que occorre na sociedade, discernimento e sagacidade na 
apreciação dos phenomencis observados, tacto e medida na deliberação sobre as providencias a adoptar, promptidão no resolver, mas resolver com clara comprehensão das necessidades do Estado, eis o que é indispensavel para um estadista .

Alguns ha, e são os que raramente apparecem, os de quem são avaros os seculos, que possuem vistas largas, vasto descortino, originalidade, profundeza, talento inventivo e facilidade em comprehender, á primeira vista, todas as consequencias de qualquer medida. $\mathrm{O}$ piloto que, ao rugir do vendaval, oscilla sobre a direcção a dar ao navio, o general que, ante um inimigo poderoso e habil, hesita sobre as ordens de que dependem a vida de milhares de homens e a honra de sua patria, estão longe, em responsabilidade do politico a quem foi confiada a direcção de um Estado. Vamos desenvolver éstas idéas de um modo prático, quasi só empiricamente.

12) Supponhamos o caso simples de augmento de producção. Dispensamos a hypothese de outras circumstancias cooperantes para a formação da crise. Tomemos o caso da superproducção do café. Não falaremos na superproducção geral, espantalho dos socialistas, quando suppunham que, com o capitalismo e o desenvolvimento das machinas, seria o mundo victima de uma pletora de productos, pois hoje todos os economistas provaram com a exactidão dos argumentos mathematicos, ser isto simplesmente um phantasma ridiculo. Temer este mal é tão absurdo quanto foi temerem as rans, ao tempo de um eclipse do sol, que, do enlace do astro rei com a lua, nascessem muitcs soes, que, com seus raios ardentes, seccariam as lagôas. Dada a superproducção de um só artigo, como o café no Brasil, ou de um conjuncto de artigos, como são os productos de industrias fabris nos Estados Unidos, ou dos productos agricolas na Republica Argentina, superproducção que a ultima guerra veiu mostrar ser muito menor do que se dizia, cumpre dar 
remedio ao caso, e ninguem melhor do que o Brasil conhece os damnosos effeitos da superproducção do café. Qual este remedio? Não podemos recorrer a panacéas, usar um unico remedio para todas as crises. Com os cartells e com os trusts obtemos alguns resultados, em dadas hypotheses, mas noutras elles são inteiramente inefficazes.

Quanto ao nosso café, varias foram as medidas indicadas: queimal-o, reduzir a exportação, tomal-o por conta do Governo. Emfim a opinião victoriosa foi a da reducção da cultura. Dizia-se que era medida radical, efficacissima, e que combateria a monocultura, um grande mal, como sabemos todos. Deu a medida resultado? Sem duvida produziu alguns beneficos effeitos immediatamente, mas não conseguiu remover o mal. $\mathrm{O}$ remedio, dentre os indicados, certamente mais efficaz, mas que não foi adoptado por ser de difficil applicação, era a procura de novos mercados. Provado que havia ainda muitos mercados para onde exportar o producto, este era incontestavelmente o melhor dos remedios.

Ninguem isto ignora, mas, na vida social, é, por vezes, mais difficil executar, com firmeza e prudencia, uma medida, do que ideal-a. Já por vezes, no decurso deste artigo, temos feito allusão á difficuldade de proporcionar a producção á prosura. Com a crescente divisão do trabalho, summamente difficil é que se tenha exacta noticia do que será o consumo de um producto. As estatisticas, a imprensa com informações quotidianas, os conselhos do pessoal competente a quem deve recorrer a autoridade que se interessa pela sorte do povo, são outros tantos meios de esclarecer os productores sobre o modo por que devem dirigir sua actividade. Algumas regras são intuitivas: todos comprehendem que devem produzir artigos para o inverno na estação propria, e que o gelo terá maior consumo no verão. Assim mesmo, por vezes, ha, a tal respeito, erros incriveis. Refere Miss Martineau 
que de Manchester pard o Rio de Janeiro foram enviados, em poucas semanas, artigos de que os consumidores não teriam necessidade em 20 annos. Zomba, porque de Birmingham foram mandados para o nosso ardentissimo clima da capital aquecedores e fazendas proprias para climas frios. Diz que de Sheffield recebeu o Rio de Janeiro patins proprios para patinar em gelo. (Vae por conta de Miss Martineau). Emfim, termina com estas palavras que valem a pena de citação: "China and cut glass were, in some places, pressed upon the natives, as preferable to cocoa-nut-shells and cow-horns, wich had hitherto been their dishes and drinking vessels". Fere isto nosso amôr proprio, mas mostra que até os inglêses commettem, neste particular, graves erros.

Para deixarmos este assumpto, diremos que, si é ridiculo o temor de superproducção geral, é fundado e sem remedio directo o que succede em relação ao augmento colossal de producção de .certos artigos pela descoberta de machinas. Basta lembrar o que diz Carrol Wright em seu relatorio de 1886 sobre a crise, referindo que, com a machina Mc-Kay fazia um operario sapateiro 60 vezes mais serviço do que trabalhando com a mão. Para isto só ha remedios indirectos.

13) Muitas vezes é o consumo que diminue subitamente. O resultado é o mesmo que o dado pela hypothese anterior.

Exemplo temos, neste ultimo anno, em nosso paiz, onde os estabelecimentos industriaes se viram forçados a diminuirem o numero de operarios por falta de consumo para seus productos. Caso em exiremo difficil é este. Dentre as muitas soluções, ha a da intervenção do Estado, tornando-se industrial, deslocando os operarios de um serviço para outro, o que é uma das maiores responsabilidades que se póde propor um administrador. Os mais habeis encontram nisto difficuldades. E' quasi só nos 
empecilhos encontrados na pratica que acha o direito ao trabalho opposição em ser reconhecido, como sendo um dos fundamentaes ou originarios. Não têm, quasi nunca, os Estados intervindo sinão muito fracamente nessas crises originadas da diminuição de consumo, e deixam, ao contrario, sua resolução ás forças vivas do paiz. Conhecem todos a historia das taboas de logarithmos organizadas ou elaboradas pelos officiaes barbeiros, em uma época em que não tinham freguezia, e em que podiam rever com cuidado provas typographicas. E', em ponto minimo, o exemplo do modo por que actuam as forças naturaes neste genero de perturbações sociaes.

14) Póde se dar um desequilibrio entre a quantidade de numerario existente e as necessidades economicas de um paiz. A consequencia será embaraçar-se a relação entre a offerta e a procura, ou perturbarem-se as trocas, pois, como é elementar em Economia Politica, nada mais faz o dinheiro do que facilitar as trocas.

Cumpre pois que mantenhamos uma quantidade de numerario proporcionada ás necessidades economicas de um paiz. Qual o meio de conseguir isto? Todos sabem que se accentua a preoccupação para obter melhoramento do meio circulante. Na Inglaterra, o cheque, conseguiu, até certo ponto, trazer remedio a esta difficuldade. $\mathrm{O}$ cheque refere-se ás transacções de certo vulto, ainda que com elle paguem os homens de fortuna todas as suas contas, sendo mesmo prova de đistincção não as solver com dinheiro. Entretanto ainda restam infinitos negocios sujeitos á sorte dos pagamentos em moeda corrente. Fala-se muito nos bancos emissores que conhecem melhor do que o Thesouro, do que o Governo, as necessidades da vida economica de um Estado: "They are in immediate contact with commercial and industrial operations, and must have a full understanding of their various needs and conditions from time to time?". Mas... quantos inconvenientes têm os bancos emissores? Arma é esta de dois 
gumes: o problema é saber si offerecem mais vantagens do que desvantagens. Hoje está se falando no contabilismo. Este, porém, está ainda muito longe de ser medida que se possa agora pôr em pratica: é para tempos que não podemos prevêr. Si o estadista, digno de tal nome, seguir os preceitos da Sciencia da Administração, procurando informar-se de tudo o que se passa na sociedade que dirige, si possuir as qualidades eminentes a que nos referimos acima, si tiver essa centelha divina que faz os grandes homens, manterá sempre o meio circulante de accôrdo com as necessidades do paiz que dirige. Si não podemos, por agora, determinar qual será o melhor systema monetario, estamos comtudo em condições de dizer que o idéal buscado pelos economistas inglêses é o que ell'es denominam elasticity of the currency, ou a capacidade do numerario para se alargar, ou restringir, de accôrdo com as necessidades do momento.

Além dessa qualidade, preoccupa, tambem, aos economistas dar-se esta adaptação tanto quanto possivel automaticamente, livre das influencias deleterias da Politica: "The system is better", diz Burton, "which works automatically as far as possible, and eliminates in the greatest degree the management of the currency from the field of political discussion".

Repetiremos: até certo ponto, acóde o oheque a esses requisitos. Deve portanto, antes de termos coisa melhor, ser seu desenvolvimento proiegido pelo Estado.

15) Acabamos de falar da importancia dos cheques dentro de um certo limite. Isto nos leva a observar que não é raro certas medidas produzirem resultados até um ponto, e dahi em diante serem inteiramente improficuas. Lembra-nos a nossa Caixa de Conversão em torno da qual tanta disputa se travou. Os factos vieram provar que era um apparelho proprio para prestar serviços em tempos normaes; que foi realmente de utilidade para o commercio importador, mas que, em momento de crise, 
era verdadeira casca de noz em mar encapellado. Por outro aspecto, tambem são de limitadissimo alcance os cartells e os trusts. Só se referem a um grupo de industriaes, e portanto não pódem fazer face, ás crises em geral, mas isto não será motivo para os condemnar, pois, como acima dissemos, não ha um remedio universal para todas as crises. Por outro motivo, porém, pódem ser condemnados: tolhem a producção com desvantagem para o bem estar do paiz. Constituem medidas empiricas de resultados immediatos vantajosos, mas de consequencias remotas damnosas para o organismo social? Como se vê, o problema é analogo ao dos bancos emissores.

16) Dar-se-ão as crises com certa regularidade de rhythmo, com certa periodicidade? E' tendencia do espirito humano vêr regularidade onde a natureza póe irregularidades .

Em rélação ás crises ésta periodicidade foi sempre defendida e com presuppostos sem nenhum fundamento. Em 1662 já sustentava Sir William Petty que ellas se repetiam em cada 7 annos, quiçá inspirado na Biblia. Mais tarde houve defensores do periodo de 10 ou 12 annos. Fundou-se na observação da periodicidade das crises em Inglaterra nos annos de 1815, 1825, 1836, 1847 , 1857 e 1866. Nós aqui tivemos a aurea Bolsa em 1890, e uma miniatura della cerca de 20 annos depois. A doutrina das manchas do sol como elementos de influencia na producção em nosso planeta, defendida por summidades, entre as quaes devemos referir Jevons, longe está de merecer confiança. O que é verdade é que as crises se dão, como era de esperar, com muito mais frequencia nos paizes novos, de vida intensa, do que nos antigos. A impossibilidade em estabelecermos nós brasileiros uma periodicidade das grandes safras do nosso principal producto, é motivo sufficiente para banirmos de nosso estudo, como elemento para combater as crises, sua regularidade no tempo, occupando-nos com outros remedios, certos de que 
a calamidade cahe sobre nós de um momento para outro inesperadamente, verdadeiro raio quando o céo está claro, limpido, sereno, azul, sem uma unica nuvem. E' bom não darmos falsa segurança. Não conhecemos ainda as leis das voltas das crises.

17) Que concluir de quanto acaba de ser exposto? Que as crises accentuam-se agora, neste momento de febre economica, mas que, si as sciencias que estudam os phenomenos economicos se mantiverem na altura do progresso social, reorganizarão o systema actual, de accôrdo com as necessidades do progresso humano, e as crises serão então muito menos graves do que o foram no seculo XIX, e do que estão sendo neste começo do seculo XX. Tiraremos um simile da sciencia penal e da criminalogia.

O crime brutal, o homicidio a mão armada, o roubo em toda sua grosseria e outros attentados graves contra a propriedade, acharam sua definição nos codigos penaes mantidos pela tradição. Hoje o crime tornou-se mais culto, mais civilisado, de cidade, revestido de rara astucia. Actos altamente graves para a vida social, attentados tão importantes quanto os brutaes da época primitiva, contra a honra, contra a propriedade e contra a vida que foram definidos em formulas precisas nos antigos codigos, não acham artigo em nossas leis penaes em que possam ser postos, não são figuras delictuosas previstas em nossas leis. Estes equivalentes do crime antigo deverão ser, dentro em pouco, reprimidos por qualquer modo, sob pena de serem profundamente perturbadas as relaçōes sociaes. Pois bem! E' á sciencia penal que toca tal estudio, acompanhando o progresso social. Do mesmo modo é á Economia Politica que cabe melhorar as condições do systema economico de accôrdo com o progresso vertiginoso destes ultimos tempos, estudando cada desarranjo que se der, e vendo qual o remedio menos perigoso, de consequencias menos damnosas para o corpo social. 


\section{$-636-$}

Tenhamos comtudo presente que quem quizer tomar remedio que nenhuma consequencia damnosa tenha para o organismo, deve se abster de qualquer medicação, e remetter-se ás forças da natureza, como fazem os individuos originaes que dizem não crêr na Medicina. Si ha máos medicos, si ha estadistas ineptos, não significa isto que não sejam importantes sciencias a Medicina e a Economia Politica.

Aperfeiçoemo-nos no estudo das sciencias economi. cas, e nosso paiz será grande, e as crises não serão de temer.

Braz de Sousa Arruda,

Docente da Faculdade. 